\title{
Pegylated Citric Acid Dendritic Architecture for the Delivery of Cytarabine in Targeting the Cancer Cells
}

\author{
B. Narasimha Rao ${ }^{1 *}$, K. Ravindra Reddy ${ }^{2}$, K. B. Chandra Sekhar ${ }^{3}$ \\ ${ }^{1}$ P. Rami Reddy Memorial College of Pharmacy, Kadapa, Andhra Pradesh, India. ${ }^{2}$ CES College of Pharmacy, Kurnool, Andhra Pradesh, India. \\ ${ }^{3}$ Oil Technological Research Institute, JNTUA, Anantapuramu, Andhra Pradesh, India.
}

\author{
ARTICLE INFO \\ Article history: \\ Received on: 13/02/2017 \\ Accepted on: 28/04/2016 \\ Available online: 30/05/2017 \\ Key words: \\ Cytarabine, Acute myeloid \\ leukemia, PEGylation, \\ Antimetabolite, Generation.
}

\begin{abstract}
Current progress in nanotechnology provides a new hope for the substantial development in the success of cancer therapy particularly in controlling tumor growth and development. PEGylated citric acid dendrimers are biocompatible compounds being developed with an aim to target the myeloid cells, from which leukemia starts and spreads. Developed dendrimers also overcome the limitations observed with usual cancer therapies like drug leakage during circulation and short circulation time in blood. Cytarabine, an antimetabolite antineoplastic agent was tightly encapsulated within the dendrimer through simple complexation and targeted to tumor cells by way of high affinity interactions. PEGylation prevents the drug leakage during circulation, bypasses RES uptake by opsonins and improves drug's stability, circulation time when administered. In present study, PEGylated citric acid dendrimers were synthesized using Divergent technique and loaded with Cytarabine. Synthesized dendrimers were evaluated for different parameters like SEM, DSC, NMR, \% drug entrapment and in-vitro drug release studies etc.
\end{abstract}

\section{INTRODUCTION}

Nanotechnology has prompted an outstanding convention of different fields like physical sciences, applied physics, biology, optics, computational investigation and modeling and materials science. As a result of this, the complex biological systems can be understood well. This understanding and manipulation of biological systems through nanotechnology offers a remarkable advancement in the diagnosis and treatment of cancers especially in controlling tumor growth and progression (Mendes, 2013). Acute myeloid leukemia is a cancer of bone marrow and blood, characterized by rapid and abnormal growth of white blood cells that accumulates in the bone marrow and further interfere with the production of normal blood cells. The incidence of AML increases with age and grows rapidly. If left untreated, AML could become fatal within few weeks to months. (George and Kurian, 2005; Scotti, 2005).

\footnotetext{
* Corresponding Author

Email: simham1985 @gmail.com
}

Cytarabine, an antimetabolite antineoplastic agent has been used for the treatment of Acute Myeloid Leukemia since 40 years. Upon administration, Cytarabine gets activated to cytosine arabinoside triphosphate through intracellular phosphorylation. Activated ara-CTP replaces deoxycytidine triphosphate that terminates the chain and blocks the synthesis of DNA and RNA resulting in leukemic cell death. For rapidly dividing cells, mitosis gets affected as the process requires DNA for replication (Ki et al., 2012). Cytosine arabinoside also inhibits enzymes like DNA and RNA polymerases and nucleotide reductase enzymes that are necessary for the synthesis of DNA. But the treatment of AML with Cytarabine is associated with some problems like adverse side-effects and resistance to therapy. Side-effects of Cytarabine include neurotoxocity, myelosupression, mucositis, acute pulmonary syndrome and other infections. In order to overcome these problems, Cytarabine is conjugated to some carriers that selectively kill the target tumor cell without harming the healthy neighbors (Hartford et al., 2009). Dendrimers, nanosized spheroid structures capable of carrying drug molecules encapsulated within its interior void spaces or attached to its external terminal groups (Shishu and Maheswari, 2009). 
They are made with a level of control, which is not possible with most linear polymers, resulting in a monodispersed, globular macromolecule with many peripheral groups. Since several years, considerable progress has been made concerning use of dendrimers in the diagnosis and treatment of cancer including the delivery of antitumor agent and contrasting agents to the target tumor cells, photodynamic therapy, boron-neutron capture therapy, photothermal therapy etc (Inoue, 2000; Agarwal and Kulkarni, 2015). Dendrimers selectively deliver the drug molecules to the tumor cells unlike chemotherapy that destroys both healthy and cancerous cells in the same way. Diagnosis of tumor cells using MRI contrast agents will be progressed with the inclusion of dendrimers as contrast agents. These novel contrast agents target the cancer cells specifically (Rao et al., 2013). Further their treelike appearance and small size provides access to each and every cell, thereby destroying the tumor cells. In addition to this, PEGylation, process of polyethylene glycol conjugation to the dendritic system enhances circulation time of dendrimers in body by resisting its recognition by opsonins. PEGylation also reduces dendrimer toxicity by masking its peripheral groups (Bharali et al., 2009; Doshi, 2011). In this study, an attempt was made to design and deliver Cytarabine loaded PEGylated citric acid dendrimers to the tumor cells and examine its influence on the invitro drug release, \%entrapment efficiency studies etc.

\section{MATERIALS AND METHODS}

\section{Materials used}

Cytarabine (Yarrow Chemicals, Mumbai), Polyethylene glycol 400 (Finar chemicals Pvt. Ltd., Ahmedabad), Sodium Carbonate, Potassium Permanganate, Thionyl Chloride,Dimethyl formamide, Propylene glycol, Tween 80 (Sd Fine Chemicals Ltd., Mumbai), Pyridine and Diethyl ether were used for the synthesis of PEGylated citric acid dendrimers. All the procured chemicals were of analytical grade.

\section{Method of Preparation}

Preparation of PEGylated citric acid dendrimers involves the following steps:

a. Synthesis of 4 generations of citric acid dendrimers

b. PEGylation of synthesized dendrimers

c. Drug loading of the PEGylated dendrimers

\section{Synthesis of 4 generations of Citric acid dendrimers}

Citric acid dendrimers can be synthesized by Divergent technique based on the established and reported procedure:

Step 1: For the synthesis of dendrimers, in a beaker $35.5 \mathrm{gms}$ of Potassium permanganate was taken and dissolved in $694 \mathrm{ml}$ of water. In another beaker, $3.75 \mathrm{gms}$ of Sodium carbonate was dissolved in $38 \mathrm{ml}$ of water. Both the solutions were mixed together with continuous stirring. To this mixture, $110 \mathrm{ml}$ of Polyethylene glycol was added and stirred on a magnetic stirrer for 3-4hrs.
The obtained mixture was cooled by immersing in ice bath at $4-5{ }^{\circ} \mathrm{C}$ for 20 minutes. As the mixture attains room temperature, it was filtered and obtained filtrate was heated on a mantle at $60-70{ }^{\circ} \mathrm{C}$ with random cooling in between. This heating and cooling was repeated till a $100 \mathrm{ml}$ concentrated liquid was obtained. The concentrate was covered with a layer of ether followed by separation of ether and aqueous layers using a separating funnel. Collected aqueous layer was heated for the complete removal of ether in a mantle at $70{ }^{\circ} \mathrm{C}$, leaving behind a white precipitate. The obtained precipitate is Polyethylene glycol diacid, a $1^{\text {st }}$ generation dendrimer.

Step 2: $1^{\text {st }}$ generation dendrimer was collected and treated with sufficient quantity of Thionyl chloride in a round-bottomed flask equipped with a condenser on a magnetic stirrer. Stirring was continued for an hour. Resultant mixture after condensation was heated to $70{ }^{\circ} \mathrm{C}$ to collect chlorinated polyethylene glycol, a G1.5 dendrimer. So collected product was made to dissolve in $20 \mathrm{ml}$ of Dimethyl Formamide and refrigerated on an icebath for 24hrs. Simultaneously, in another beaker, sufficient quantity of citric acid was dissolved in $10 \mathrm{ml}$ of DMF followed by the addition of $110 \mathrm{ml}$ of pyridine. This beaker was placed by the side of previous beaker overnight on an ice-bath in a refrigerator. Next day morning, both the solutions were taken out, mixed together and incubated for $6 \mathrm{hrs}$ at $55-60^{\circ} \mathrm{C}$ in an incubator to yield a second generation dendrimer. Thus obtained second generation dendrimer was further purified by Column Chromatography (Vijayakumar et al., 2012).

The above step is repeated with increasing amounts of citric acid and thionyl chloride for the synthesizing a 4 generations of dendrimers as shown in table 1 .

\section{PEGylation of dendrimers}

PEGylation, Polyethylene glycol conjugation to the dendrimer system is considered an important step in the construction of Dendrimers as they provide stability to the encapsulated drug with reduced drug-dendritic toxicity to the body tissues (Mishra et al., 2016; Balguri et al., 2015; Harris et al., 2003). For the purpose of PEGylation, from the above synthesized dendrimers, 1 mole was transferred to a conical flask and dissolved in $10 \mathrm{ml}$ of DMF completely. To this mixture, $5 \mathrm{~mol}$ of $\mathrm{N}, \mathrm{N}$ ' Cyclohexyl carbodimide was added and stirred thoroughly. This reaction mixture was kept aside undisturbed for 4 days at $40^{\circ} \mathrm{c}$. After 4 days, reaction mixture was taken out, stirred gently and later dissolved in $85 \mathrm{ml}$ of PEG and $150 \mathrm{ml}$ of chloroform to yield a clear solution. Obtained solution was refluxed for esterification in a RB flask for 3-4 days. Resultant mixture after esterification was filtered using a separating funnel by adding $5 \mathrm{ml}$ of water for the complete removal of $\mathrm{N}, \mathrm{N}$ - dicyclo hexyl carbodimide. 
Table 1: Formulation of Dendrimers.

\begin{tabular}{|c|c|c|c|c|c|c|c|}
\hline Formulation & $\mathrm{KMNO}_{4}$ & $\mathrm{Na}_{2} \mathrm{CO}_{3}$ & PEG400 & Thionyl chloride & Citric acid & Pyridine & DMF \\
\hline F1(G1) & $35.5 \mathrm{gm}$ & $3.75 \mathrm{gm}$ & $110 \mathrm{ml}$ & - & - & - & - \\
\hline $\mathrm{F} 2(\mathrm{G} 2)$ & $35.5 \mathrm{gm}$ & $3.75 \mathrm{gm}$ & $110 \mathrm{ml}$ & $6 \mathrm{ml}$ & $0.1 \mathrm{~g}$ & $100 \mathrm{ml}$ & $30 \mathrm{ml}$ \\
\hline F3(G3) & $35.5 \mathrm{gm}$ & $3.75 \mathrm{gm}$ & $110 \mathrm{ml}$ & $8 \mathrm{ml}$ & $0.2 \mathrm{gm}$ & $100 \mathrm{ml}$ & $30 \mathrm{ml}$ \\
\hline F4(G4) & $35.5 \mathrm{gm}$ & $3.75 \mathrm{gm}$ & $110 \mathrm{ml}$ & $10 \mathrm{ml}$ & $0.4 \mathrm{gm}$ & $100 \mathrm{ml}$ & $30 \mathrm{ml}$ \\
\hline
\end{tabular}

$\mathrm{F}=$ Formulation $; \mathrm{G}=$ Generation; $\mathrm{KMnO}_{4}=$ Potassium permanganate; $\mathrm{Na}_{2} \mathrm{CO}_{3}=$ Sodium Carbonate; $\mathrm{PEG}=\mathrm{Polyethylene}$ glycol .
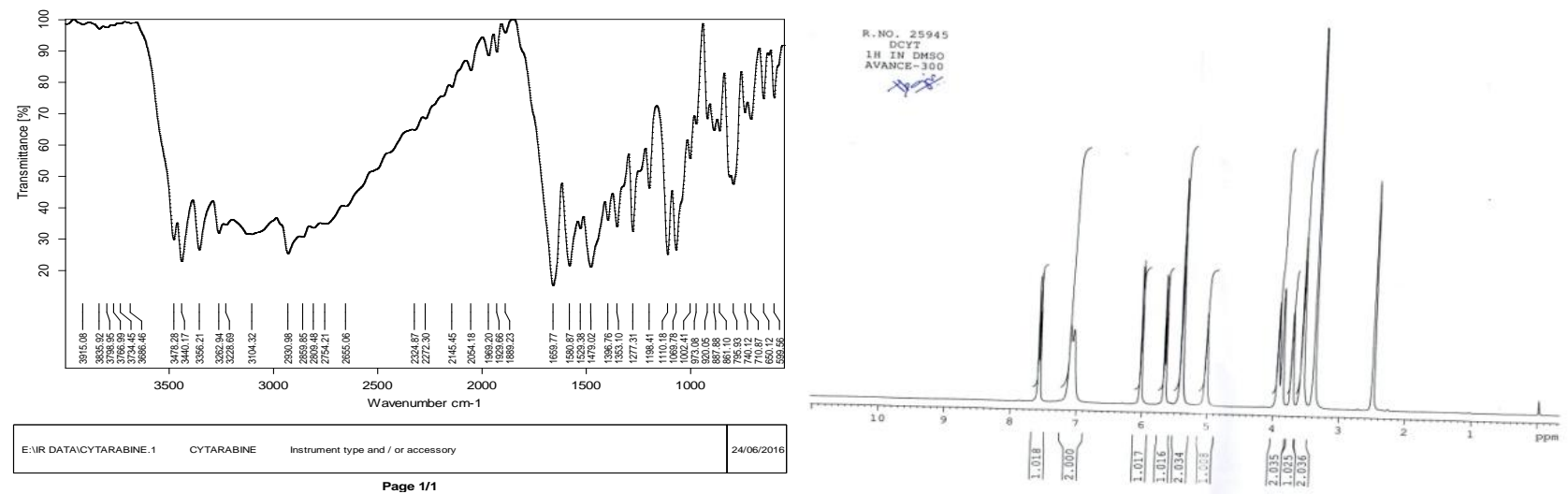

Fig. 1a and 1b: FTIR and NMR spectra of drug, cytarabine.

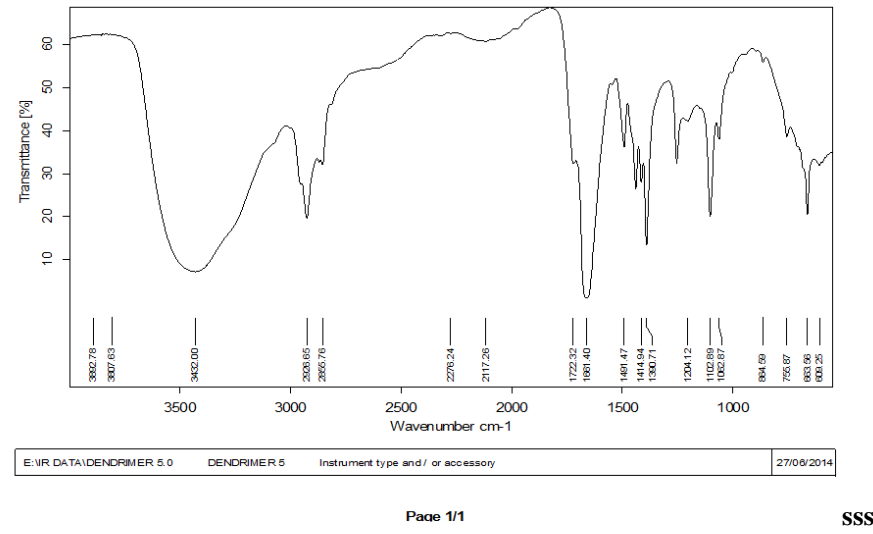

Fig. 2a and 2b: FTIR and NMR spectra of $5^{\text {th }}$ generation plain dendrimers.

\section{Drug loading in the PEGylated dendrimers}

For the purpose of drug loading, Cytarabine was dissolved in suitable solvent like distilled water and added dropwise to the dendrimer solution. The drug-dendrimer solution was stirred on a magnetic stirrer for $24 \mathrm{hrs}$ for complete encapsulation of drug into dendrimers (Rao et al., 2015).

\section{Evaluation of Synthesized PEGylated Dendrimers} following:

Synthesized dendrimers were characterized for the

\section{FT-IR and NMR studies}

FT-IR spectra of pure drug, cytarabine, plain dendrimers and cytarabine loaded PEGylated dendrimers were performed using FT-IR spectrophotometer (Bruker, Germany) in the region
$4000 \mathrm{~cm}^{-1}$ to $400 \mathrm{~cm}^{-1}$ to confirm the presence of drug and compatibility between drug and dendrimers. Drug sample was mixed with potassium bromide in the ratio of 1:100 and compressed to pellets using Hydraulic pressed pellet technique by applying 10kgs of pressure. Obtained pellet was placed under light path in spectrophotometer and spectra were recorded.

NMR spectra of cytarabine, plain dendrimer and cytarabine loaded PEGylated dendrimer were obtained by performing NMR spectroscopy using AVANCE spectrophotometer with DMSO as a solvent. NMR studies confirm the loading of cytarabine in dendrimers (Namazi et al., 2011).

\section{Morphology of Dendrimers:}

Vaccum dried cytarabine loaded PEGylated dendrimers were studied for their external morphology, shape and particle size 
using Scanning Electron Microscopy. SEM image was snapped at an accelerating voltage of $15 \mathrm{kv}$ at a chamber pressure of 10.3 mmHg (Vijayakumar et al., 2012).

\section{Percentage drug entrapment studies}

Drug entrapment studies of drug loaded dendrimers were performed using UV spectrophotometer. Percentage drug entrapment studies confirm the presence of drug in the dendritic structures. Here, drug loaded dendrimer was dissolved in $100 \mathrm{ml}$ of water and centrifuged at 5300rpm for $1 \mathrm{hr}$ using microcentrifuge. Resultant solution after centrifugation was filtered and observed under UV spectrophotometer at $280 \mathrm{~nm}$ to determine the amount of drug encapsulated in dendrimer (Reddy et al., 2014).

$$
\text { Entrapment efficiency }=\frac{\text { Amount of entrapped drug }}{\text { Total amount of drug }} \times 100
$$

\section{Zeta potential}

Zeta Potential is the measure of stability of synthesized PEGylated dendrimers and is measured using Zeta sizer. It measures the extent of attractive and repulsive forces present between the particles. Small particles possess high zeta potential value and offers stability to the preparation. Such smaller size preparations resists agglomeration and remain dispersed throughout the preparation. If the zeta potential value is small, particles experience attractive forces and experience flocculation (Zaman et al., 2014; Ciolkowski et al., 2011).

\section{Differential Scanning Calorimetry}

Thermal stability of drug and drug loaded samples over a range of temperatures can be determined by performing Differential Scanning Calorimetry studies using DSC module (DSC Q20 V24.11 Build 124, USA). In this study, known quantity of drug and drug loaded dendrimers were placed on an aluminium pan and lid was closed. Pan was placed on a sample holder, equilibrated at $35^{\circ} \mathrm{C}$.

Slowly, the temperature was raised at a rate of $10^{\circ} \mathrm{C} / \mathrm{min}$ under nitrogen gas pressure till the entire sample gets deteriorated. Resultant curves provide information regarding stability and phase transitions of the studied samples (Ciolkowski et al., 2011).

\section{In-vitro drug release studies}

Drug release from the PEGylated dendrimer systems can be estimated using Dialysis tube whose one end was tied to a cellophane membrane. Suitable quantity of drug loaded PEGylated dendrimer was taken in the dialysis tube and immersed in a beaker containing 9.2 buffer solution maintained at $37{ }^{\circ} \mathrm{c}$. This assembly was placed on a magnetic stirrer rotating at $100 \mathrm{rpm}$. As diffusion proceeds, samples were withdrawn at regular intervals from the medium and replaced with fresh media. Amount of drug release at fixed time intervals was estimated using analytical methods like UV spectrophotometer (Karthikeyan et al., 2016).

\section{RESULTS AND DISCUSSION}

\section{Synthesis of citric acid dendrimers (FTIR and NMR studies)}

Citric acid dendrimers were synthesized as per the method described by B. Narasimha Rao et al. IR and NMR data proved the synthesis. IR spectrum $(\mathrm{KBr}) ; 1146.49 \mathrm{~cm}^{-1}$ for $\mathrm{C}-\mathrm{O}$; $1249.51 \mathrm{~cm}^{-1}$ for $\mathrm{CH}_{2}$ rock; $1460.36 \mathrm{~cm}^{-1}$ for $\mathrm{CH}_{2}$ scissor; 1662.48 $\mathrm{cm}^{-1}$ for $\mathrm{C}=\mathrm{O}$ stretch and $1960.97 \mathrm{~cm}^{-1}$ and $2515.14 \mathrm{~cm}^{-1}$ for $\mathrm{CO}_{2}$ as shown in fig.3a. ${ }^{1} \mathrm{H}$ NMR spectrum of $5^{\text {th }}$ generation citric acid dendrimer showed chemical shifts of protons of citric acid at 2.9$2.4 \mathrm{ppm}\left(\mathrm{CH}_{2}\right)$ as a quartet and protons of polyethylene glycol at 3.9-3.2 ppm (- $\left.\mathrm{OCH}_{2} \mathrm{CH}_{2} \mathrm{O}-\right)$. Absence of signals at 8.8-8.5 ppm indicates that acidic groups of citric acid dendrimers have been interacted with the drug molecules.

In ${ }^{1} \mathrm{H}$ NMR complex of drug loaded dendrimer, there are 4 series of proton absorption related to drug molecule. On the other hand, acid functionality peaks of citric acid have totally disappeared in G5 cytarabine dendrimer complex, which is an evidence for the chemical interaction between drug as a guest and dendrimer as a host.

\section{Morphology of dendrimers}

Morphology of both plain and PEGylated citric acid dendrimers was analyzed by SEM. Shape and nature of dendrimers was found spherical and smooth with particle size ranging between $22-76 \mathrm{~nm}$.

\section{Percentage drug entrapment studies}

Results of percentage drug entrapment carried through UV spectroscopic method was in the range 13.4 - 62.1\%. Drug entrapment was high for fourth generation PEgylated dendrimer i.e., $62.1 \%$. As the generations increase, more polymer will be available for binding with the drug. Thus, entrapment efficiency increases as the generation number increases.

\section{Zeta potential}

Zeta potential of Cytarabine loaded PEGylated dendrimers was carried using Zetasizer and the technique adapted was Dynamic Light Scattering Technique. Obtained values were in the range of +37 to +48 , indicating good stability of the formulations. Credit for the good stability was contributed to the small size of dendrimers that resist agglomeration.

\section{DSC studies}

DSC studies were performed for the pure drug, Cytarabine and drug loaded PEGylated $4^{\text {th }}$ generation dendrimer. The resultant curves suggested that Cytarabine loaded PEGylated dendrimer is not a physical mixture.

Upon heating to $220^{\circ} \mathrm{C}$, Cytarabine experienced an endothermic transition, which was previously referred as melting point of the substance, indicating the purity of the drug. Characteristic peaks of Cytarabine were almost disappeared in the drug loaded formulation. 

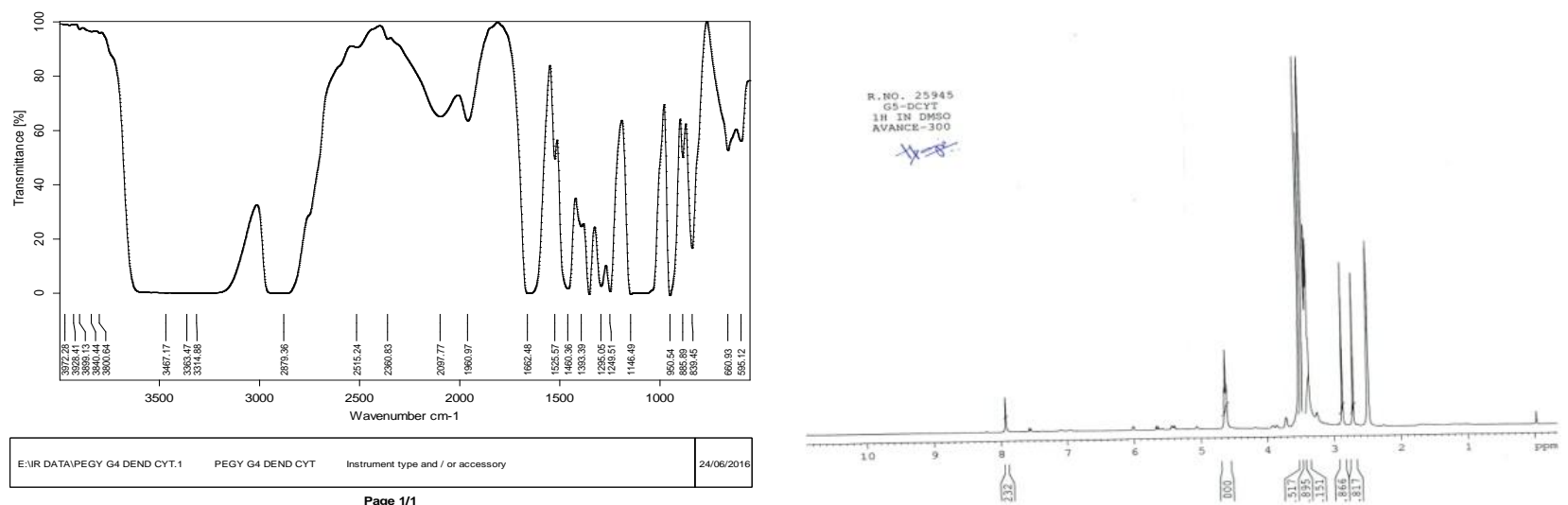

Fig. 3a and 3b: FTIR and NMR spectra of $5^{\text {th }}$ generation cytarabine loaded PEGylated dendrimers.

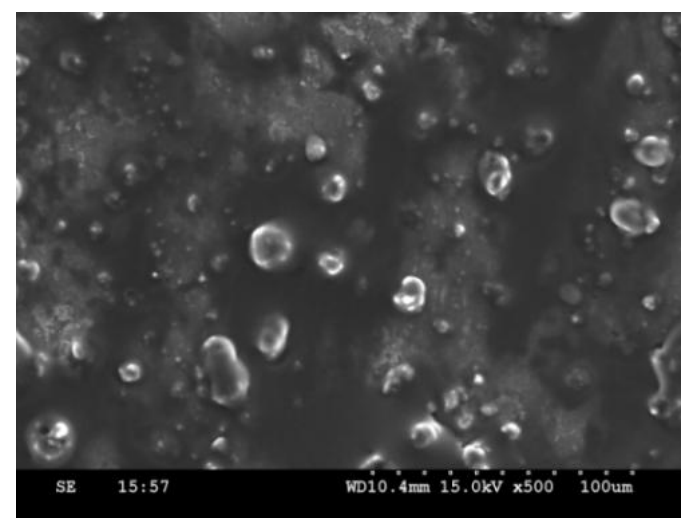

Fig. 4: SEM image of Cytarabine loaded PEGylated $5^{\text {th }}$ generation dendrimer.
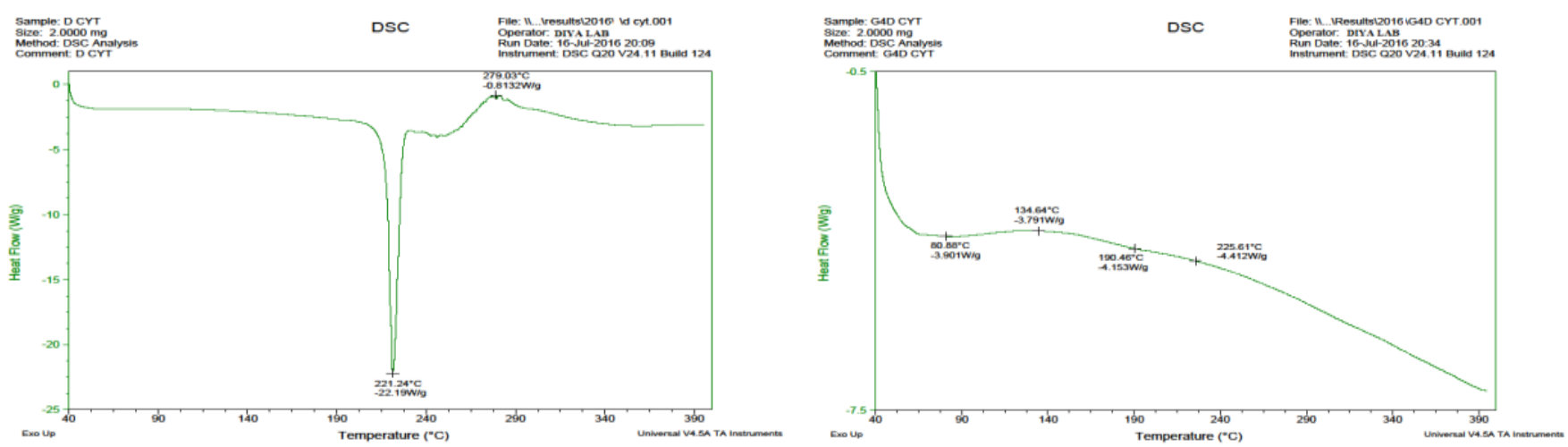

Fig. 5a and 5b: DSC thermogram of Cytarabine and drug loaded PEGylated $4^{\text {th }}$ generation dendrimer.

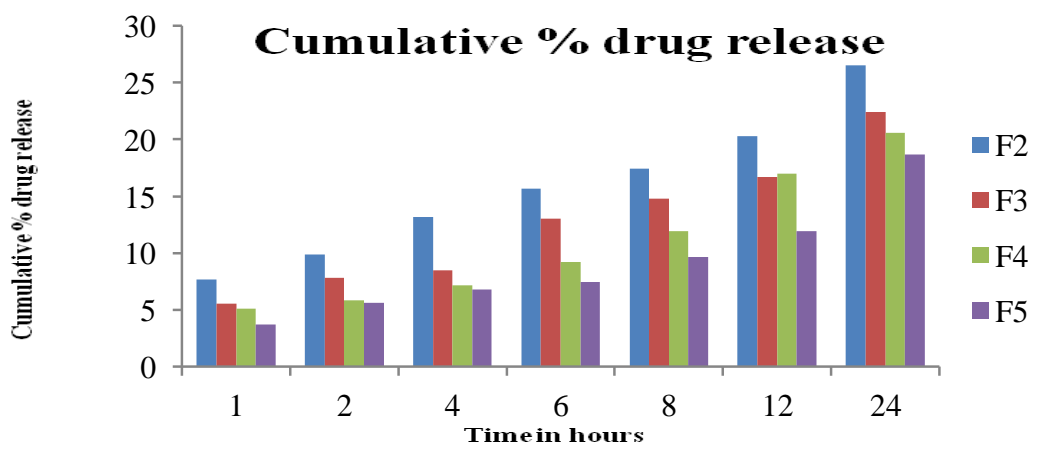

Fig. 6: Cumulative \% drug release of PEGylated dendrimers. 


\section{In vitro drug release studies}

In-vitro drug release studies were performed for G2, G3, G4 and G5 Cytarabine loaded PEGylated dendrimers using $9.2 \mathrm{pH}$ buffer as a diffusion medium. Drug release was more for fourth generation as compared to second and third generation dendrimers. This is due to the fact that as the generations increase complexicity of the dendrimers also increase exhibiting a sustained effect. Thus, sustained and controlled actions can be achieved with higher generation dendrimers.

\section{ACKNOWLEDGEMENT}

We acknowledge P. Rami Reddy Memorial College of Pharmacy for their support and encouragement throughout the course of our study.

\section{FUNDING}

This research did not receive any specific grant from the funding agencies in the Public, commercial or not-for-profit sectors.

\section{CONCLUSION}

The developed dendrimer system has been found suitable for the prolonged delivery of Cytarabine to the myeloid cells. Synthesized dendritic systems were termed as nanoparticulate drug delivery depots of Cytarabine as they maintain the drug concentration for a longer period of time.

Financial support and sponsorship: NIL.

Conflict of Interests: There are no conflicts of interest.

\section{REFERENCES}

Agarwal A, Kulkarni S. Dendrimers: A New Generation Carrier. Int J Res Dev Pharm Lifesci, 2015; 4:1700-12.

Balguri SP, Adelli G, Bhagav P, Repka MA, Majumdar S. Development of nano structured lipid carriers of ciprofloxacin for ocular delivery: Characterization, in vivo distribution and effect of PEGylation. Invest Ophthalmol Vis Sci, 2015; 56:2269-2269.

Bharali DJ, Khalil M, Gurbaz M, Simone EM, Mousa SA. Nanoparticles and Cancer Therapy: A Concise Review with emphasis on Dendrimers, Int J Nanomed. 2009; 4: 1-7.

Ciolkowski M, Rozanek M, Szewczyk M, Klajnert B, Bryszewska M. The influence of PAMAM-OH Dendrimers on the Activity of Human Erythrocytes ATPases. Biochem Biophys ActBiomem, 2011; 1808:2714-23.

Doshi M. Dendrimer and its Application. Int J Pharm Sci Rev Res, 2011; 7:104-11.

George N, Kurian L. An Approach to Detect Acute Myelogenous Leukemia in Blood Microscopic Images. IOSR J Comp Eng, 2016;1-4.
Harris JM, Chess RB. Effect of pegylation on pharmaceuticals. Nat Rev Drug Disc, 2003; 2:214-221.

Hartford CM, Duan S, Delaney SM, Mi S, Kistner EO, Lamba JK. Population-specific Genetic Variants Important In-susceptibility to Cytarabine arabinoside Cytoxicity. Blood, 2009; 113:2145-53.

Inoue K. Functional Dendrimers, Hyperbranched and Star Polymers. Prog Polym Sci, 2000; 25:453-571.

Karthikeyan R, Reddy AMS, Koushik OS. Novel Cefixime Loaded Citric Acid Dendrimer for Antibacterial Activity against Pseudomonas Aeruginosa and Staphylococcus aureus. Nanomed Nanotech Op Acc, 2016; 1:1-8.

Kim KI, Huh IS, Kim IW, Park T, Yoon SS, Yoon JH et al., Combined Interaction of Multi-locus Genetic Polymorphisms in Cytarabine Arabinoside Metabolic Pathway on Clinical Outcomes in Adult Acute Myeloid Leukemia (AML) patients. Europ J Canc. 2012; doi: 10.1016/j.ejca.2012.07.022.

Mendes PM. Cellular Nanotechnology: Making Biological Interfaces Smarter. Chem Soc Rev, 2013; 42:9207-18.

Mishra P, Nayak B, Dey RK. PEGylation in anti-cancer therapy: An overview. Asian J Pharm Sci, http://dx.doi.org/10.1016/j.ajps.2015.08.011.

Namazi H, Motamedi S, Namvari M. Synthesis of New Functionalised Citric Acid-based Dendrimers as Nanocarrier Agents for Drug Delivery, Bioimp. 2011; 1:63-9.

Rao BN, Viswanath V, Purushothaman M, Vaishnavi VP. Synthesis and Formulation of New Functionalized Citric acid based Dendrimers for Drug Delivery using an Antibacterial agent. World J Pharm Res, 2015; 4:1054-62.

Rao S, Bhushanam K, Das UN, Prasad TNVKV, Rao KS. Recent Advances of Nanoparticles in Cancer Therapy and Diagnosis. J Med Sci Res, 2013;95-102.

Reddy MS, Tejaswi Y, Kalyan AV, Sravya R, Namrath M. Novel Drug Delivery of Minocycline against bacteria by using a Polymer Citric acid Macromolecule. Ind J Res Pharm Biotech, 2014; 2:1161-6.

Scotti F. Automatic Morphological Analysis for Acute Leukemia Identification in Peripheral Blood Microscopic Images. Proc CIMSA, 2005:96-101.

Shishu, Maheswari M. Dendrimers: The Novel Pharmaceutical Drug Carriers. Int J Pharm Sci Nanotech. 2009; 2: 493-502.

Vijayakumar P, Choudary RK, Narne R. Efavirenz Loaded Novel Citric Acid dendritic Architecture for Increased Solubility and Sustained Delivery. J Pharm Drug Del Res, 2012; 1:1-5.

Zaman M, Ahmad E, Qadeer E, Rabbani G, Khan RH. Nanoparticles in relation to Protein and Peptide Aggregation. Int $\mathrm{J}$ Nanomed, 2014; 9:899-912.

\section{How to cite this article:}

Rao N, Reddy R, Sekhar C. Pegylated Citric Acid Dendritic Architecture for the Delivery of Cytarabine in Targeting the Cancer Cells. J App Pharm Sci, 2017; 7 (05): 189-194. 